

\section{DEPLOYMENT PLATFORM:}

For deploy this application I used amazon web services. Amazon web services provide servers on rent to deploy application. Amazon web services is the one of the popular cloud based platform that provide on-demand cloud computing platforms to individuals, companies and governments, on a paid subscription basis.

Platform: amazon web services (Ec2 instance Ubuntu 16.4 servers)

\section{RELATED WORK :}

This mainly used for school department or university department. This project I use many operations for keeping department faculty records as well as student's records. In this application faculty have to fill student's information like students profile, attendance report, activity report or exam related information. Department head can see any information related to faculty or student anytime so using this application can save time. Department can send any important announcement to faculty or students any time.

\section{EXISTING SYSTEM STATEMENT}

\section{AND}

PROBLEM

In the existing scenario the head of the department should enter everything in excel sheets and registers papers so it's very hard work and taking so much time. Then staff enters corresponding subject's attendance, activity report, exam report and result of students entered in the excel sheets and validations are to be done by the user itself. So there will be a lot of work to be done and must be more conscious during the entrance of details. it requires a lot of laborious work. And maintain these record is very hard job and more risk is involved.

\subsection{PROBLEM STATEMENT :}

In earlier time, the college was using the manual system, which was based on the entries on the registers and excel sheet so that handle these records is very hard task and challenging there is so risk involved. So that using department management application can store these records on cloud and access any time and no need to do all work manually. On cloud departments all information is kept securely. This application making easy department's work. iii. Handle volume of information

iv. Complexity of data processing.

v. Processing time constant.

vi. Computational demand.

vii. Instantaneous queries.

viii. Security features.

\section{THERE ARE FOUR PANEL.}

\section{DEPARTMENT HEAD /ADMIN PANEL:}

This panel handle by department head that can access information about faculty and students. Department head having authority to assign account to faculty and students. If faculty and students want to login account then first time have to send request to department head then department head assign user id or password to login account. In this panel department head can send important announcement to faculty and students.

\section{ADMIN LOGIN:}

Department management application service provider provide user id or password to department head for admin panel.

Description: Authorization screen: Admin must enter username and password for authentication.

Input: Username and Password.

Processing: Validate username and password

Output: user id and password is correct then will get welcome panel otherwise error: invalid credentials please try again

Boundary: Username: $[\mathrm{A}-\mathrm{Z}][\mathrm{a}-\mathrm{z}][0-9]$ \& minimum of 6 , maximum of 20 characters.

Password: $[\mathrm{A}-\mathrm{Z}][\mathrm{a}-\mathrm{z}][0-9]$.

ADMIN HOME SCREEN: Admin is allowed to select one of the following operations:

ANNOUNCEMENT MESSAGE: Department head can send important announcement to faculty portal and students portal.

Faculty report: in this tab department head can able to see all information about faculty. This is especially for faculty information like faculty profile and salary management operation.

STUDENT REPORT: In this tab department head can access students report like that students profile attendance report, activity report and exam marks. 
EXAM REPORT: In this tab department head can access exam result. all classes student's exam related information using students roll number or name.

\section{FACULTY PANEL :}

Faculty can access faculty panel using user id and password that provide by admin or department head. Faculty work is fill students profile, daily base attendance, activity report, assignment report and exam marks. Faculty can send message to student panel related to class, assignment, marks and university holidays.

\section{STUDENT PANEL ;}

Student can access student panel using USNNUMBER and password (password provide by department head or admin). Students can able to see his profile, his attendance report, activity report and exam marks using student panel. If students having any query then can send any message to department head using students panel.

\section{OTHER PANEL:}

This panel can be use by guest user without login. Guest user can be get information of college infrastructure, admission process, academics, department, and available course and branches. And guest user can be get information of university course's details, fees structure and university information. Guest student can download admission form from this panel.

\section{FLOW CHART:}

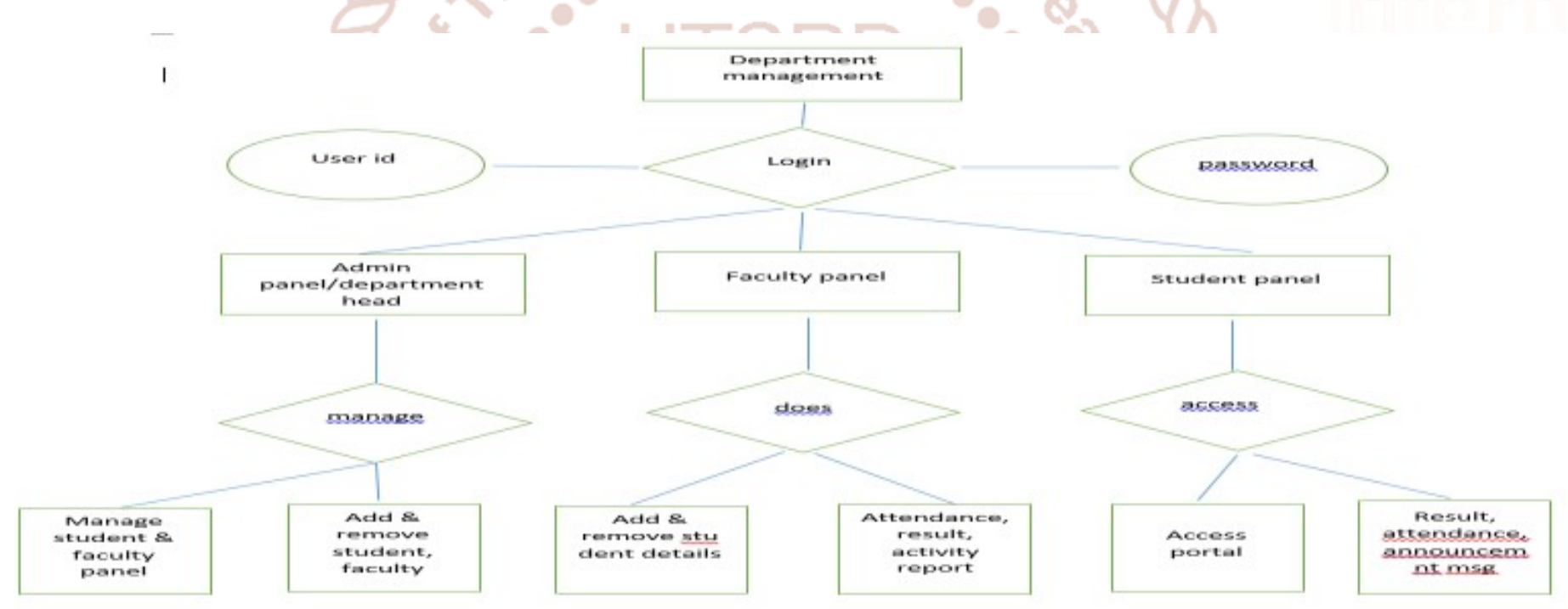

Departmemt management application

\section{IMPLEMENTATION}

The implementation involves the experimental results of the proposed scenarios, in this report experimental result shown in snapshot of each module. The implementation of proposed methodology done with the user interface by creating the web pages as a user interface which satisfies the theoretical analytics into practical.

\section{LOGIN PAGE:}

Which involves login form of user and admin by entering their username and password after entering submit button it goes to their respective home page.

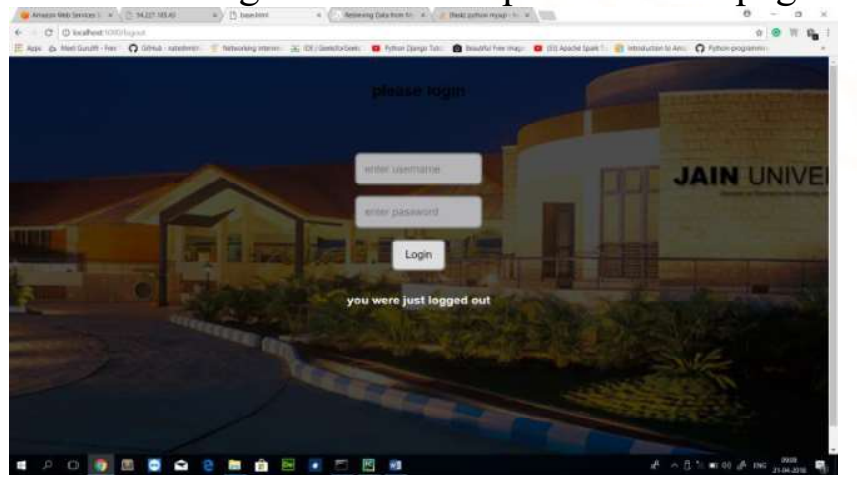




\subsection{DEPARTMENT HEAD PANEL:}

\subsubsection{ADMIN HOME PAGE:}

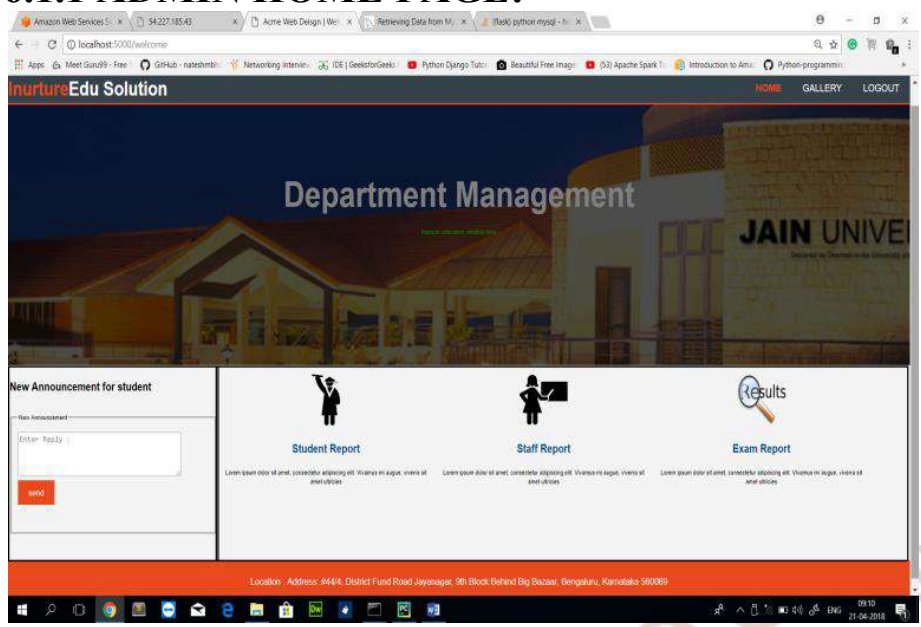

After successful login by admin page redirects to the admin home page which involves navigation menus such as Manage User, User Permission. Admin home page is use for department head that have all permission of the department management application. In this panel department head can able to see information about student report, staff report, and exam report. Using this panel department head can send any announcement to student panel as well as staff panel and having permission to assign account to student and faculty.

\subsubsection{STUDENT PROFILE:}

Admin can able to see student profile, result, attendence, all information about student using usn number or name.

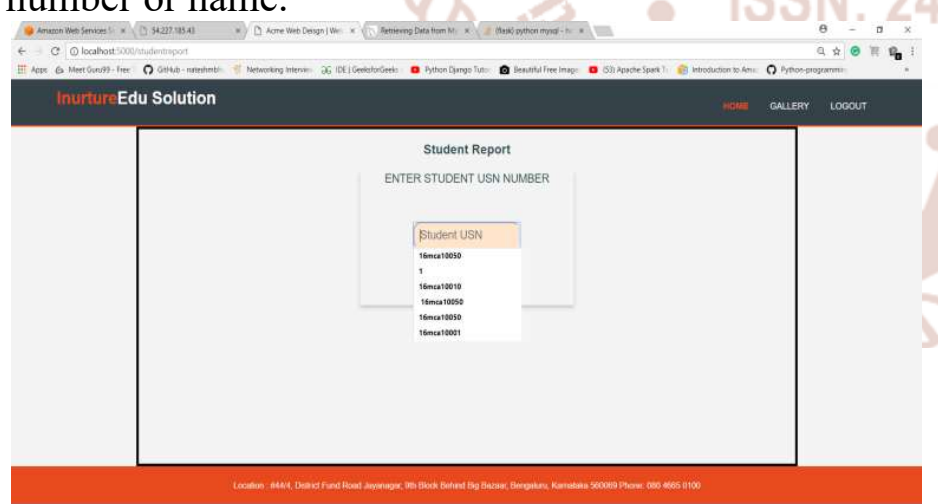

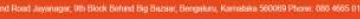

\section{STUDENT PROFILE:}

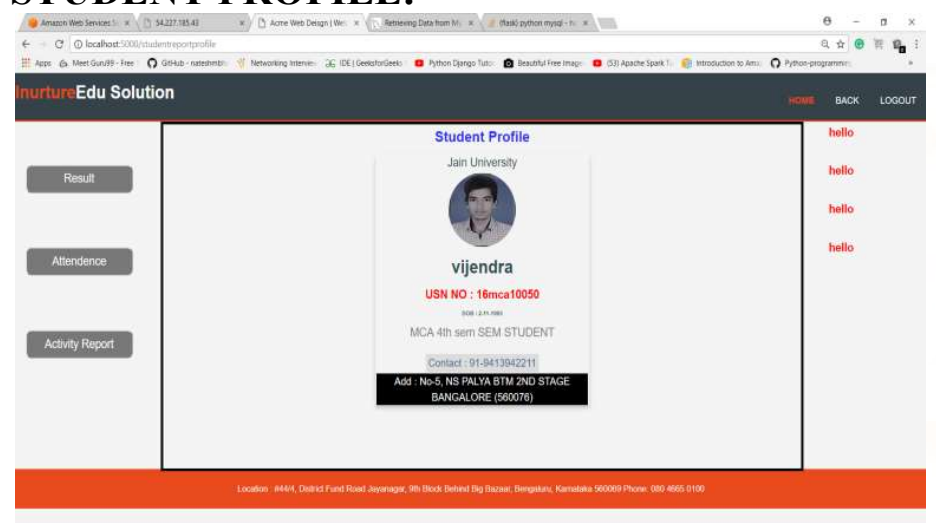

*

\section{STUDENT ATTENDENCE:}

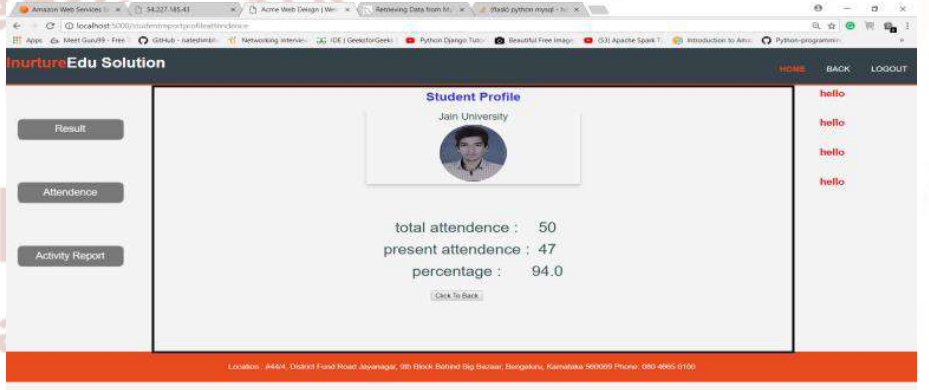

6.1.3 FACULTY REPORT: In this panel admin can see information about staff faculty like that staff member profile, salary related report.

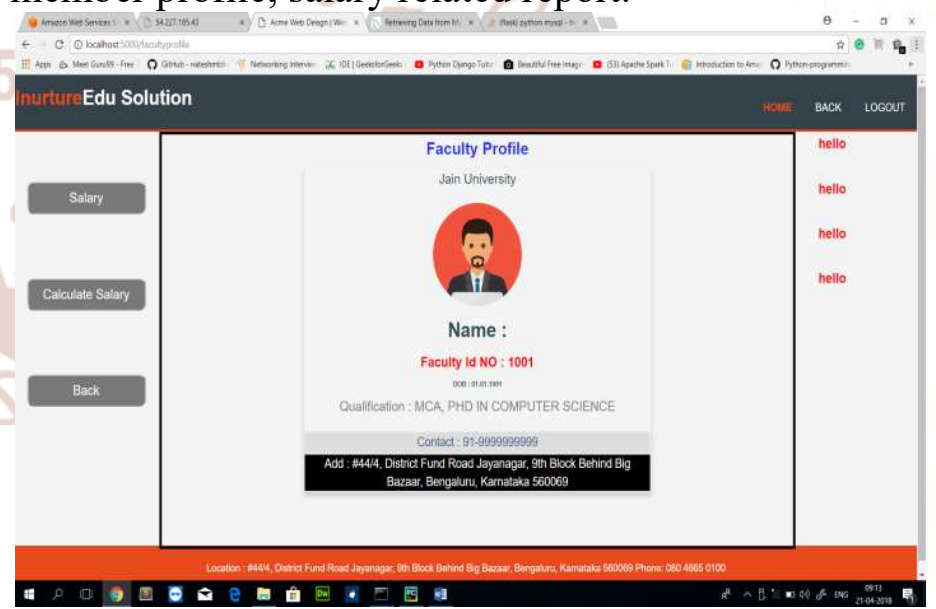

6.1.4 RESULT REPORT: using student usn number or name admin can able to see students result. 


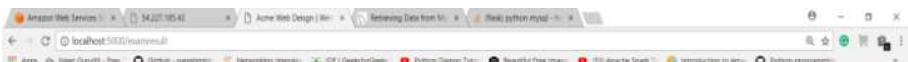
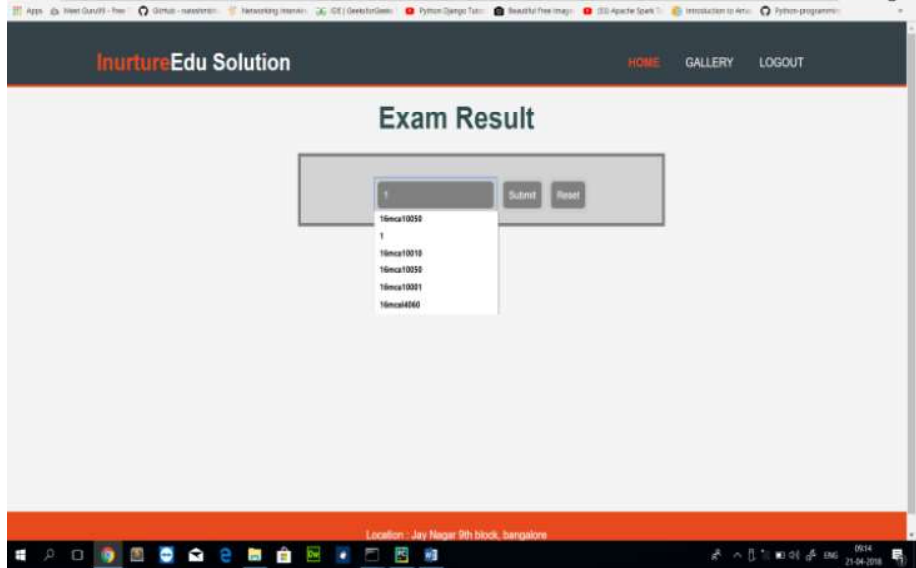

Students result using USN Number

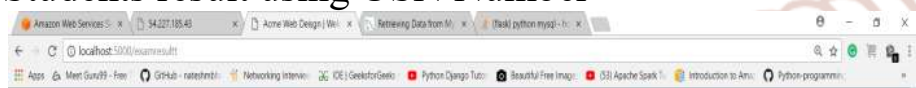

Edu Solution

GMLERY LOCOUT

Exam Result

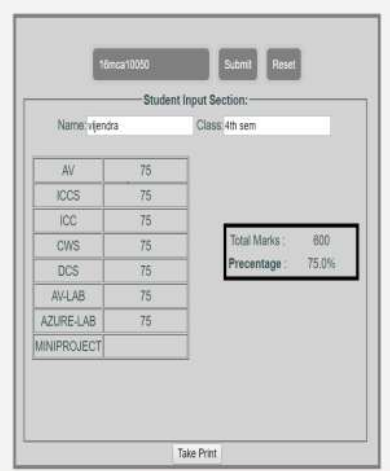

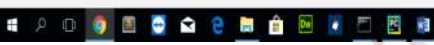

6.2 FACULTY PANEL: faculty panel is use for department faculty. Using user id and password faculty can access this portal that user id or password provided by admin or department head. In this portal faculty have to add information about student like that student profile, result, attendance and activity report. Using this panel faculty can able to send any announcement message to student portal.

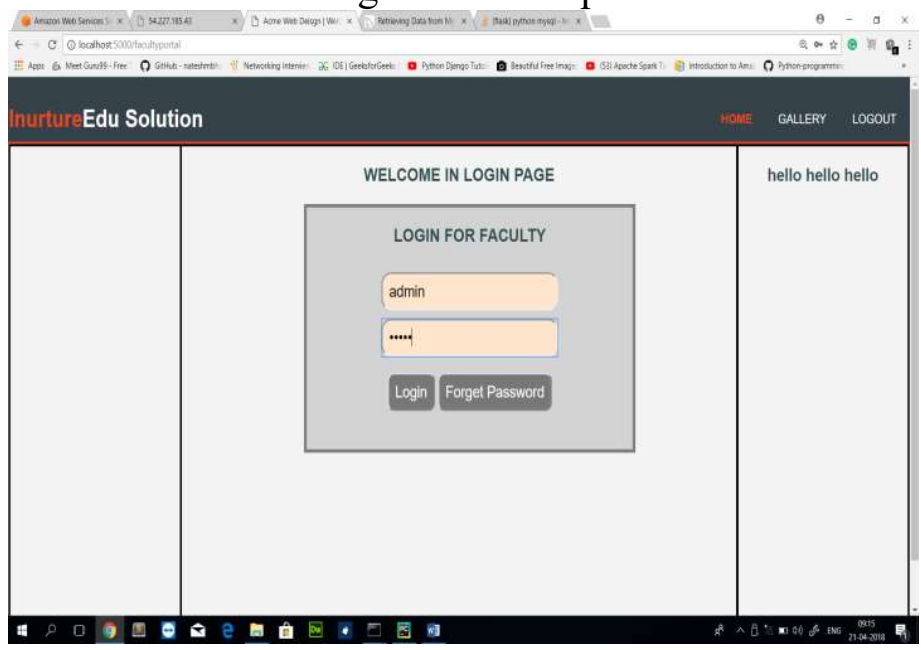

FACULTY PORTAL: ADDING STUDENT PROFILE - In this panel faculty can add new student profile and can update, delete existing student profile.

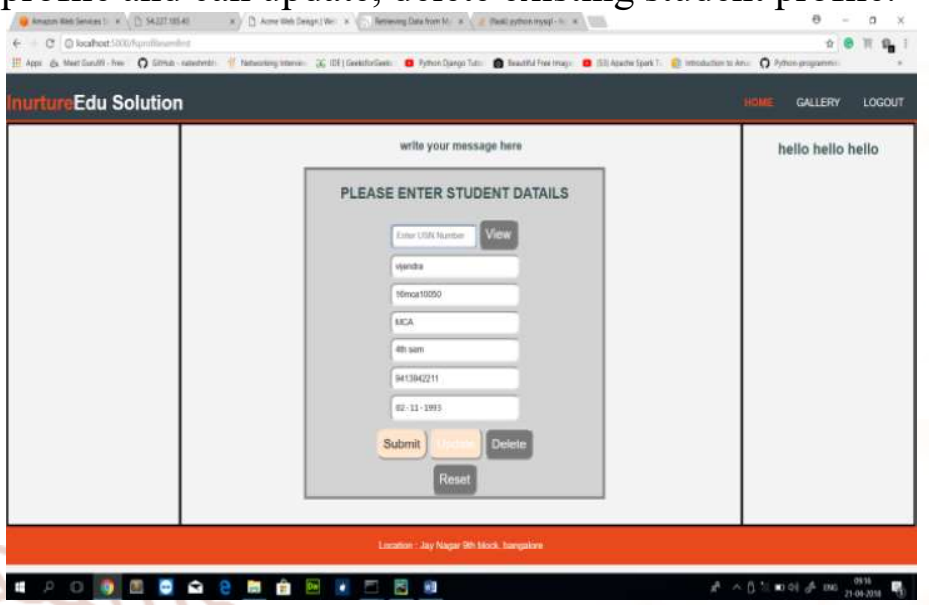

FACULTY PORTAL: ADDING STUDENT RESULT - In this panel faculty can add new student result and can update, delete existing student result.

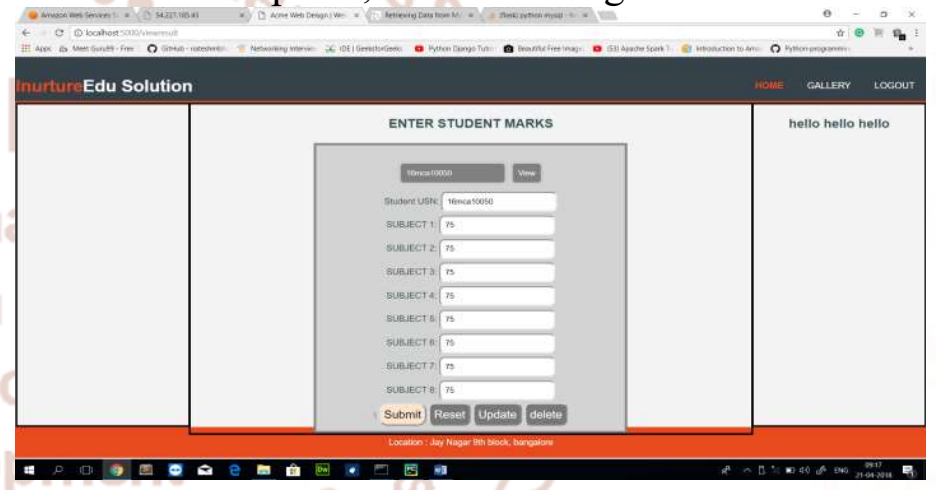

FACULTY PORTAL: ADDING STUDENT ATTENDENCE - In this panel faculty can add new student attendence.

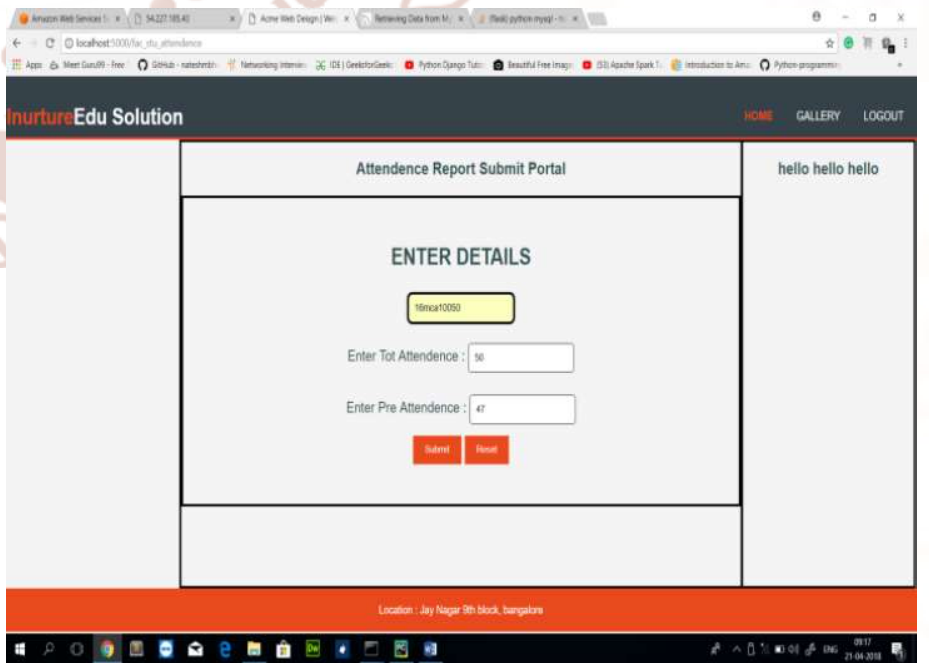

So that in faculty portal all details add to faculty manualy to his subject wise and class wise. 
6.3 STUDENT PORTAL: In this portal student have to login with his USN Number and password that provide by admin. Using this portal student can able to see his profile, result, attendence report and can see announcement from department head.

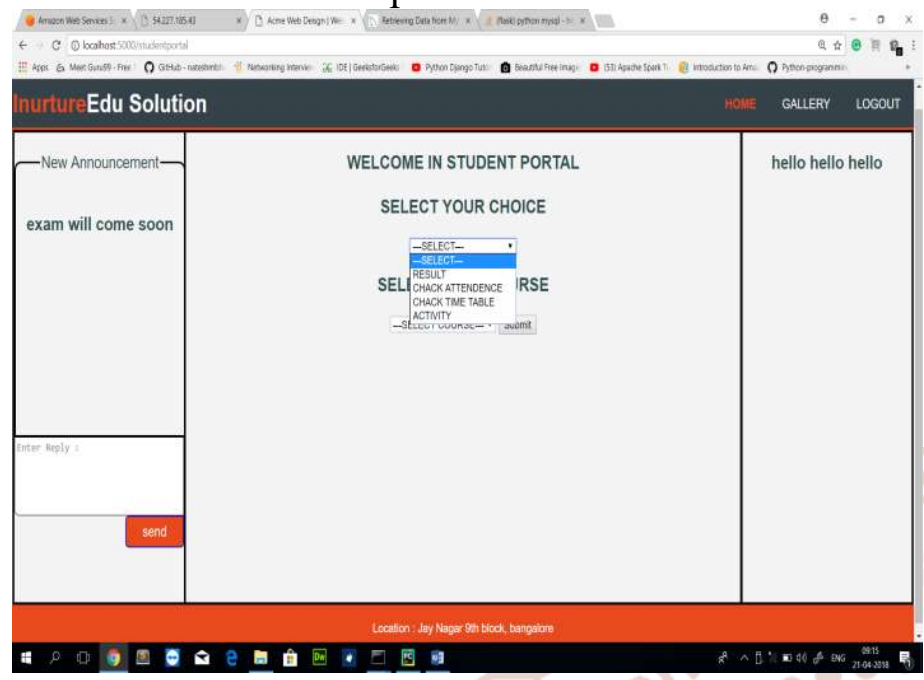

\section{CONCLUSION AND FUTURE WORK}

The overall speedup is considerably higher than manual work. The department management system enhances the functionalities of the routine works of the department in a number of ways. The computerization helps the users a lot to minimize the working time with ease and handle complex process easily. The department staff get information in desired manner. And student will get information easily. Data retrieval is also easy and fast. This also restricts the users to enter invalid data and reduces the burden on the department. The data maintaining has been made quite simple such as searching of records and records maintenance. The error rate reduced dramatically with the use of department management system.

According to feature need I will do work on this application. In feature I want to implement some other things that will make this application easy and more useful.

\section{REFERENCES}

1. Muhammad Baqer Mollah, Kazi Reazul Islam, "Next Generation of Computing through CloudComputing Technology" 2011 IJC.

2. Igor Ruiz-Agundez, Yoseba K. Penya and Pablo G. Bringas, "A Flexible Accounting Model for Cloud Computing" 2009 IJCER.

3. Xing $\mathrm{Wu}$ and Dou wanchan, "Pricing as a Service: Personalized Pricing Strategy in Cloud Computing" 2012 IEEE.

4. Hao Lu, ,Xing Wu, Wu Zhang, "Optimal Pricing of Multi-model Hybrid system for PaaS Cloud computing" 2012 IEEE.

5. Atsuo Yoshitaka and Tadao Ichikawa, ASurvey on Content-based Retrieval forMultimedia Databases, IEEE Transactions onKnowledge and Data Engineering, 11(1999)81-93.8)

6. W,Qi, L. Gu, H. Jiang, X. Chen, and H.Zhang, Integrating Visual, Audio, and TextAnalysis for News Video, Proc. of IEEEInternational Conference on ImageProcessing, 2000, pp. 1013.9)

7. D.Wactlar, T. Kanade, M. A. Smith, and S. M.Stevens, Intelligent Access to Digital Video:The Informedia Project, IEEE Computer, 29(5) (1996) 46-52.10)

8. H. Rein-Lien, M. Abdel-Mottaleb, A. K. Jain,Face Detection in Color Images, IEEETransactions on Pattern Analysis and MachineIntelligence, 24 (5) (2002) 696-706 